\title{
A comparative study between experimental and theoretical buckling load for hollow steel column
}

\author{
Sudhir Kumar Kashyap ${ }^{1}$, Sajal Kumar ${ }^{2}$ Mousumi Mallick ${ }^{3}$, Rudra Pratap Singh ${ }^{4}$, \\ Manoranjan Verma ${ }^{5}$ \\ ${ }^{I}$ CSIR-Central Institute of Mining \& Fuel Research, Barwa Road, Dhanbad-826015, INDIA \\ ${ }^{2}$ Birsa Institute of Technology, Sindri, Dhanbad-828123, INDIA \\ ${ }^{3}$ CSIR- Central Institute of Mining \& Fuel Research, Barwa Road, Dhanbad -826015, INDIA \\ ${ }^{4}$ CSIR-Central Institute of Mining \& Fuel Research, Barwa Road, Dhanbad-826015, INDIA \\ ${ }^{5}$ CSIR-Central Institute of Mining \& Fuel Research, Barwa Road, Dhanbad-826015, INDIA \\ Correspondence e-mail: sudhirnutan@yahoo.com
}

\begin{abstract}
Hollow mild steel columns of same outer diameter and length but different wall thickness show the buckling behavior in different manner in the fix-fix end condition. The behavior of the column is in good agreement with Rankine's formula. Additionally, there is a very strong relation between actual buckling load and buckling load by Rankine's formula. There is some difference between the theoretical and actual buckling load which may be due to geometrical defect, crack generation, chemical composition and formation of eccentricity. Columns show that the variation of differences between actual and theoretical buckling load with respect to wall thickness is parabolic in nature.
\end{abstract}

Keywords: Hollow column, buckling load, compaction behavior, chemical composition, wall thickness.

DOI: http://dx.doi.org/10.4314/ijest.v10i3.3

\section{Introduction}

In this paper an effort has been made to study the compaction behavior and actual buckling load of the hollow mild steel columns having same length and outer diameter but different thin wall thickness of the given composition for Fix-Fix end condition. Additionally, more emphasis has been given to study on comparative analysis of Euler's and Rankine's buckling load with actual buckling load. Apart from these an attempt has also been made to study the trend analysis of actual and theoretical buckling for this end condition. As per literature reviewed it is found that the mild steel column having slenderness ratio less than 80 follow the Rankine's formula in good manner but greater than the 80 follow the Euler's formula in good manner (Khurmi, 2005) Euler column buckling can be applied in certain regions and empirical transition equations are required for intermediate columns. For very long columns the loss of stiffness occurs at stresses far below the material failure (Akin, 2009; Optics, 2018). The buckling behavior of steel column depends on different types of cross section and wall thickness (Avear, 2014; Johnson, 2018; Bystrom and Kuzmin, 2013). The effect of axisymmetric imperfection and generation of eccentricity on the buckling behavior of a circular cylindrical shell under axial compression (Hutchinson et al., 1971)

The initial geometric imperfections, other sources of imperfection such as the misalignment of loading, boundary conditions, material properties and variability of thickness are also responsible for the scatter and reduction in buckling load of shell structure (Palassopoulos, 2018; Morris, 1996; Li et al., 1997; Elishakoff; Arbocz and Stamer). Ansys software is based on the Timoshenko theory and this theory involves shear stress geometric imperfection and residual stresses. Euler's theory neglects these things, so Ansys gives accurate buckling load then Euler's buckling load (Bhoi and Kalurkar, 2014). Buckling strength depends on the direction of the load and HAM is an effective analytical approach to solve the buckling load (Basbiik et al., 2014; Eryilmaz et al., 2013). Buckling strength depends on the direction Structural steel columns having same length and different wall thickness there is 
decrease in actual buckling load due to crack and orientation of crack (Estekanchi and Vafai, 1999). Buckling of cylindrical shell Reinforced with elastic liner (Kim, 2011). Apart from these it has been seen that error in straightness in column can be taken as L/1000.And the error in straightness decreases the buckling strength in several of end condition .The effects of geometry and loading imperfections on the Response and lower-bound buckling load of a compression- load cylindrical shell, concluded that geometrical and loading imperfection decrease the buckling strength of in significant amount (Bassem et al., 2015). To study the buckling behavior experimentation has been done for the fix-fix end condition, on five mild steel hollow column of length 1520 $\mathrm{mm}$, same outer diameter of $60 \mathrm{~mm}$ and having different thin wall thickness 1.6,1.8,2.6,2.9 and $3.3 \mathrm{~mm}$. The chemical composition of each column is shown in table given below Table 1 shows the different percentage of carbon, silicon, manganese, phosphorus and sulphur. The Figure 1 follows the different hollow mild steel columns.

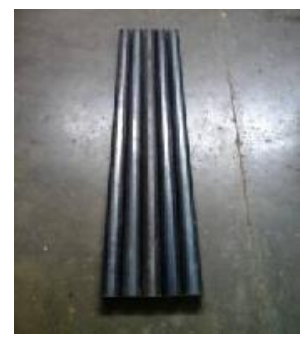

Figure1. Hollow mild steel column

Table 1 Chemical composition of hollow mild steel columns

\begin{tabular}{cccccc}
\hline Column & $\mathrm{Si} \%$ & $\mathrm{Mn} \%$ & $\mathrm{C} \%$ & $\mathrm{P} \%$ & $\mathrm{~S} \%$ \\
\hline 1 & 0.0224 & 0.203 & 0.0418 & 0.0110 & 0.0062 \\
2 & 0.0205 & 0.215 & 0.0496 & 0.0273 & 0.0095 \\
3 & 0.0234 & 0.254 & 0.0514 & 0.0263 & 0.0090 \\
4 & 0.0214 & 0.463 & 0.0574 & 0.0224 & 0.0043 \\
5 & 0.0283 & 0.227 & 0.0485 & 0.0258 & 0.0066 \\
\hline
\end{tabular}

\section{Experimentation}

To find the experimental value of buckling load experimentation is done on the 100 Ton vertical compression testing machine as shown in Figure 2. The specifications of this machine are given below.

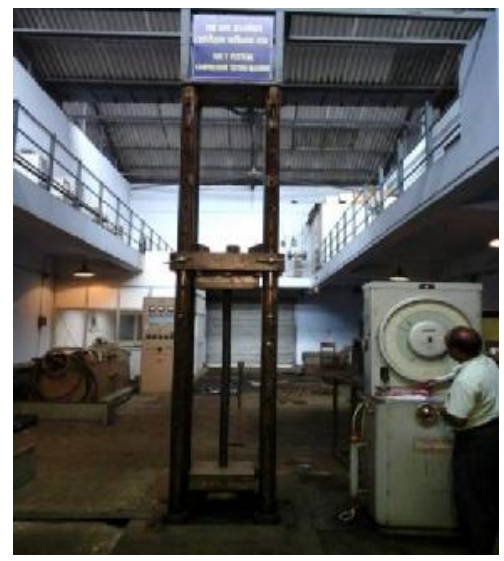

Figure 2100 Ton vertical compression testing machine

Specification of 100 ton vertical compression testing machine:

Capacity-100 Tonnes

Voltage-440

Cycles-50

Number-E 6/1015
CMRI/SDT43/CTM-01

Phase-3

Type-7IN48DCJ

The Table 2 shows the experimental buckling load of the given columns. The graph obtained by the machine during the experimentation has been given below in the figure 3 to 7 which shows the behavior of the compaction of the columns as the load increases and the actual buckling of the columns having wall thickness $1.6,1.8,2.3,2.9$ and $3.3 \mathrm{~mm}$ respectively. 
Table 2 Actual or experimental buckling load of different wall thickness columns

\begin{tabular}{|c|c|c|}
\hline Column & Wall thickness ( mm.) & Experimental Buckling load (Ton) \\
\hline 1 & 1.6 & 6.0 \\
\hline 2 & 1.8 & 7.5 \\
\hline 3 & 2.3 & 11.5 \\
\hline 4 & 2.9 & 14.7 \\
\hline 5 & 3.3 & 18.0 \\
\hline
\end{tabular}

Machine range is fixed in 20 Ton, $\mathrm{X}$ axis shows the compaction and $\mathrm{Y}$ axis shows the buckling load. One small division of $\mathrm{Y}$ - axis is 0.1 ton for each experimentally obtained buckling load i.e $6,7.5,11.5,14.7$ and 18 ton for column 1 to 5 respectively.

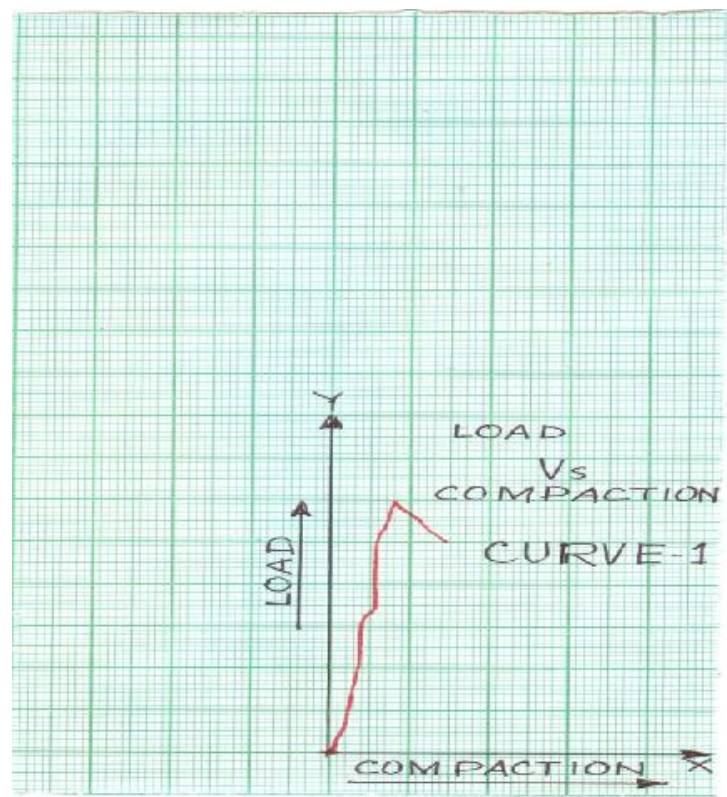

Figure 3 Buckling and compaction of column 1

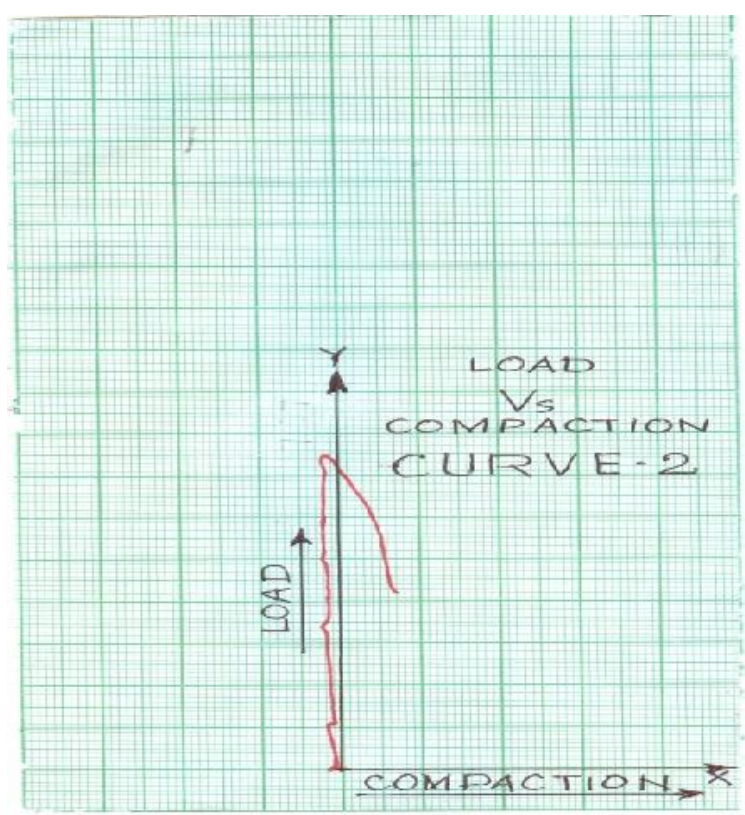

Figure 4 Buckling and compaction of column 2

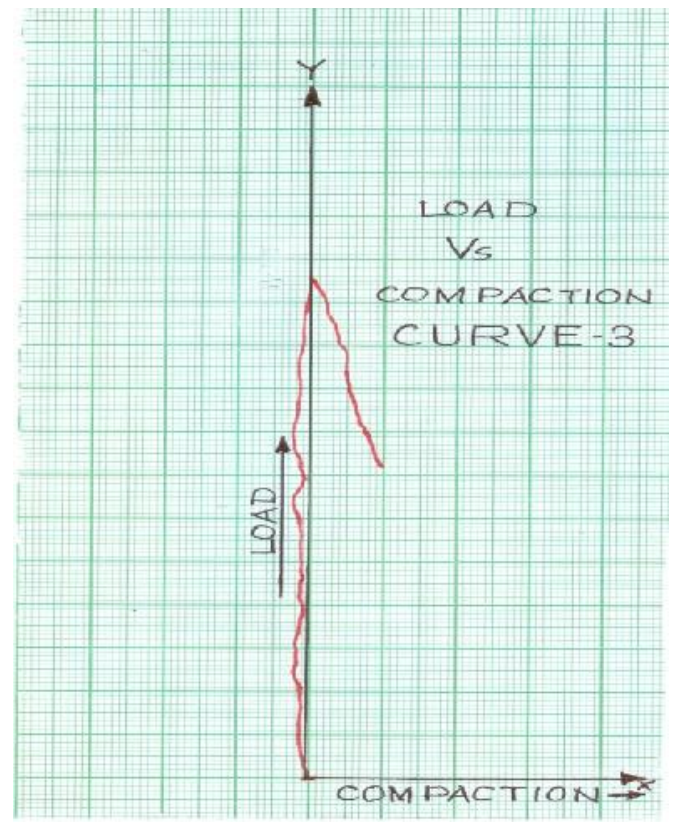

Figure 5 Buckling and compaction of column 3

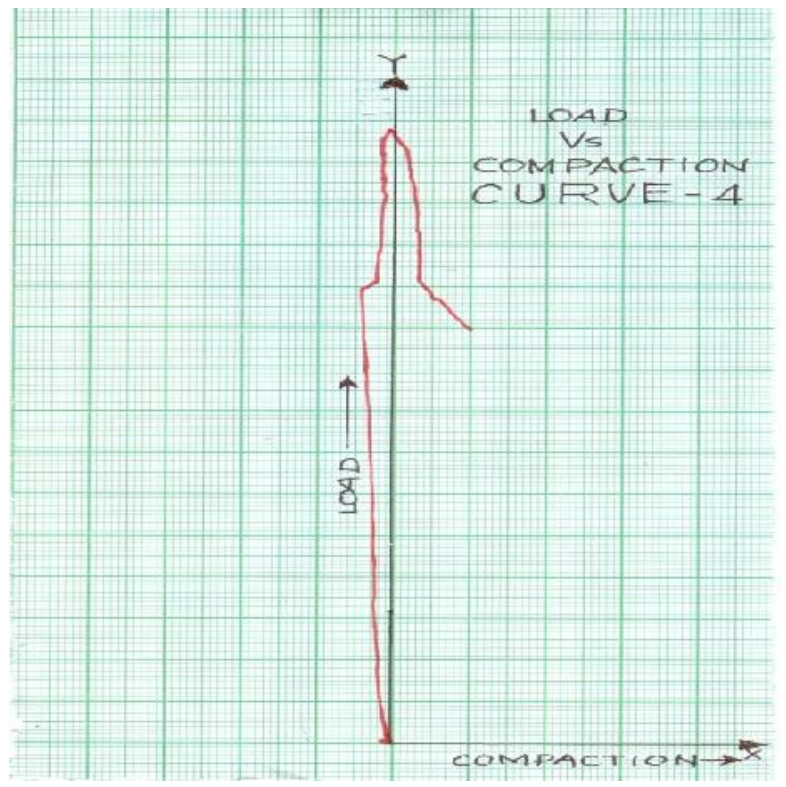

Figure 6 Buckling and compaction of column 4 


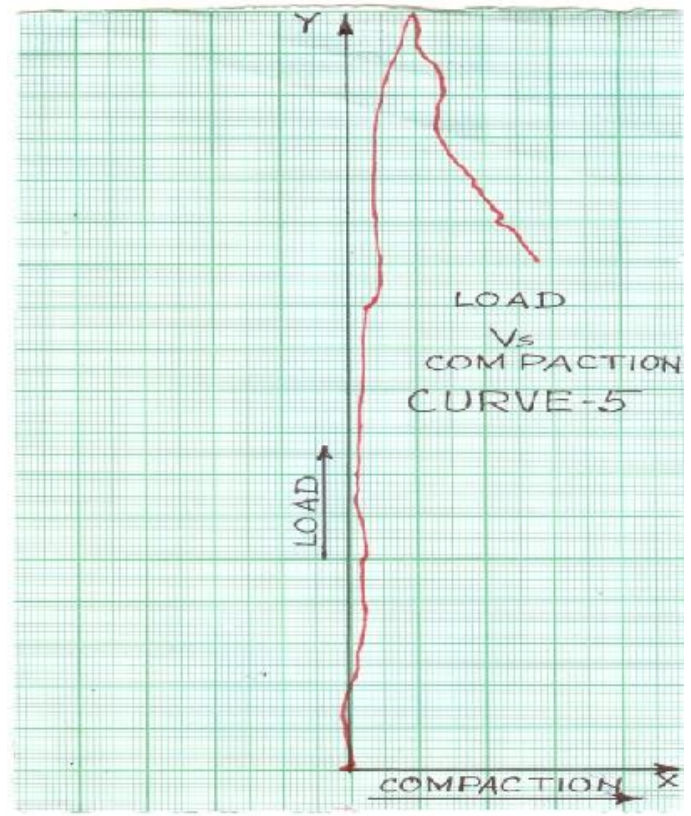

Figure 7 Buckling and compaction of column 5

\section{Agreement of actual buckling load with euler's and rankine's formula}

\subsection{Theoretical buckling load by using Euler's equation}

$F($ Buckling $)=\frac{K \pi^{2} E l}{L^{2}}=\frac{K \pi^{2} E A}{\left(\frac{L}{r}\right)^{2}}$

Whereas $k$ is the Euler's constant, $E$ is the young's modulus of elasticity, $I$ is the moment of inertia, A is the cross sectional area , $L$ represents the length and $r$ is the radius of gyration of the column. With the help of given geometrical parameters of columns area of cross section, radius of gyration and slenderness ration are calculated and then by putting in the Euler's formula theoretical buckling load is calculated. The table 3 shows the buckling load by Euler's formula.

Table 3 Buckling load by Euler's Formula

\begin{tabular}{|c|c|}
\hline Column no & $\begin{array}{c}\text { Buckling load according to } \\
\text { Euler's formula.(Ton) }\end{array}$ \\
\hline 1 & 43.34 \\
\hline 2 & 48.27 \\
\hline 3 & 60.14 \\
\hline 4 & 74.64 \\
\hline 5 & 82.00 \\
\hline
\end{tabular}

The value of theoretical buckling load calculated by Euler's formula differs very high with respect to the actual load. The Table 4 shows the difference between theoretical Euler's buckling load and actual buckling loads.

Table 4 Difference between actual and theoretical Euler's buckling load

\begin{tabular}{|l|c|c|c|c|c|}
\hline Column & 1 & 2 & 3 & 4 & 5 \\
\hline $\begin{array}{l}\text { Buckling load by Euler's } \\
\text { formula (Ton) }\end{array}$ & 43.34 & 48.27 & 60.14 & 74.64 & 82.00 \\
\hline Actual buckling load (Ton) & 6 & 7.5 & 11.5 & 14.7 & 18 \\
\hline $\begin{array}{l}\text { Difference between actual and } \\
\text { theoretical }\end{array}$ & 37.34 & 40.77 & 48.64 & 59.94 & 64 \\
\hline
\end{tabular}

3.2 Theoretical buckling load by using rankine's equation: 
$F($ Buckling load $)=\sigma_{c} \times A / 1+a\left(L_{e v} / k\right)^{2}$

Whereas $\sigma_{c}$ denotes crushing strength, $A$ is cross sectional area, a is the Rankine's constant, $L_{e v}$ is the equivalent length and $k$ is the radius of gyration. The crushing strength of mild steel is $320 \mathrm{MPa}$. $\left(l_{e v} . / \mathrm{k}\right)$ denotes the slenderness ratio and the value of Rankine's constant is $1 / 7500$. With the help of these geometrical parameters and Rankine's formula, buckling is calculated. The Table 5 shows the buckling load by Rankine's formula.

Table 5 Buckling load by Rankine's formula

\begin{tabular}{|c|c|}
\hline Column & Buckling load by Rankine's formula (Ton) \\
\hline 1 & 8.11 \\
\hline 2 & 9.00 \\
\hline 3 & 11.2 \\
\hline 4 & 14.3 \\
\hline 5 & 16.1 \\
\hline
\end{tabular}

Table 6 Difference between actual and theoretical Rankine's buckling load

\begin{tabular}{|c|c|c|c|c|c|}
\hline Column & 1 & 2 & 3 & 4 & 5 \\
\hline $\begin{array}{c}\text { Buckling load using } \\
\text { Rankine's formula (Ton) }\end{array}$ & 8.11 & 9 & 11.2 & 14.3 & 16.1 \\
\hline $\begin{array}{c}\text { Actual buckling load } \\
\text { (Ton) }\end{array}$ & 6 & 7.5 & 11.5 & 14.7 & 18 \\
\hline Difference (Ton) & 2.11 & 1.5 & 0.3 & 0.4 & 1.9 \\
\hline
\end{tabular}

From Table 4 and table 6 it has been observed that difference of actual buckling load to the Euler's buckling load is very large but difference is comparatively lower for the Rankine's buckling load. This can be more clearly understood with the figure 8 . In this figure blue spot ,red spot and green spot represent the actual, Rankine's and Euler's buckling load respectively .All the actual buckling load points overlapped by the Rankine's buckling load points .Therefore, it is seen that there is a strong agreement between actual buckling load and the load obtained by Rankine's formula

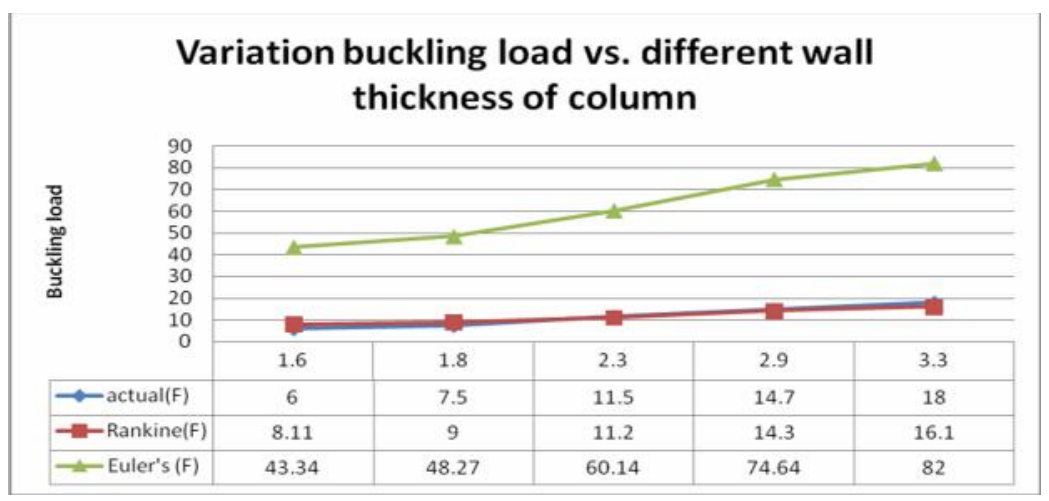

Wall thickness

Figure 8 Variation of buckling load with Wall thickness

3.3 Trend analysis of buckling load

The graph in Figure 9 shows that how much strongly actual buckling failure of these columns follows the Rankine's formula . It is observed that there is strong agreement between Rankine's formula and the actual buckling failure.

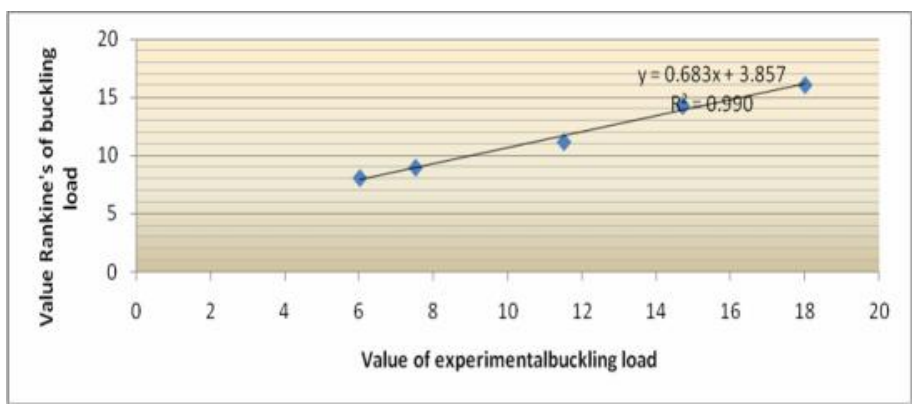

Figure 9 Trend equation of theoretical and actual buckling load 
The trend equation of theoretical buckling to the experimental buckling load is $Y=0.683 X+3.857$ and the value of co-relation coefficient is $R^{2}=0.990$. Which shows a good agreement between Rankine's formula of buckling failure and experimental buckling load.

\section{Effect of wall thickness on buckling load}

\subsection{Analysis of variation in buckling load with wall thickness}

The Figure 10 given below shows the variation of actual buckling load from the Rankine's buckling load with respect to wall thickness. It is observed that as the wall thickness increases from the 1.6 to $1.8 \mathrm{~mm}$ the rate of decrease of buckling load is very high but from 1.8 to 2.3 the rate of variation of buckling load is comparatively lower than earlier and again when the thickness increases from 2.3 to 2.9 variation is very low but from wall thickness from 2.9 to 3.3 variation rate is again become comparatively higher. Table 6 shows the variation in buckling load with respect to the wall thickness.

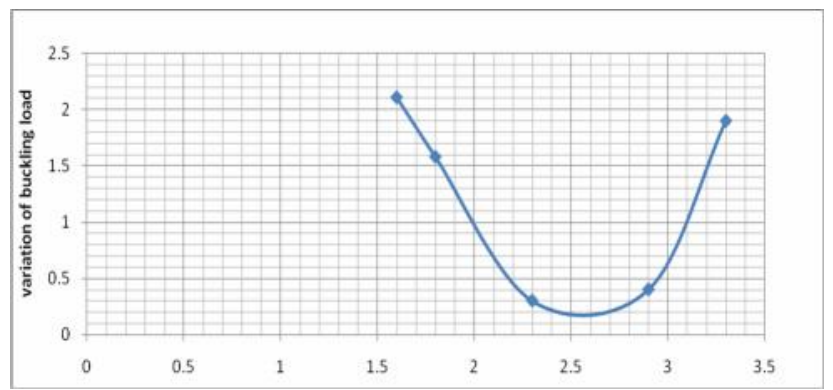

Figure 10 Variation of buckling load with wall thickness

\subsection{Factors which affects variation}

Experimentation based on the assumption that all the mild steel columns are perfect and seamless. There is no any type of crack and geometrical imperfection. But after graphical analysis it has been observed that some columns have large variation in buckling load .The reason may be human error or minor error in straightness or cross sectional error or may be due to some eccentricity. Straightness error is measured by the deviation of the column from the axis and it is given by $L / 1000$ where $L$ denotes length of the column. On the other hand cross sectional error is measured by $0.1 t$ where $t$ is the wall thickness of column. The variation in buckling load for different columns may also be due to chemical composition.

\section{Conclusion}

The buckling failure of mild steel hollow columns having different chemical composition and same outer diameter and length but different in wall thickness follow the Rankine's formula in very closely. There is a good agreement between the theoretical and experimental buckling load. The trend equation and correlation coefficient are $Y=0.683 X+3.837$ and $R^{2}=0.990$ respectively show the strong relation between actual and theoretical buckling load by Rankine's formula. The nature of variation in buckling load with respect to wall thickness as shown in figure 10 is typical a parabola. It is observed that as the wall thickness increases from the 1.6 to $1.8 \mathrm{~mm}$ the rate of decrease of buckling load is very high but from 1.8 to 2.3 the rate of variation of buckling load is comparatively lower than earlier one and again when the thickness increases from 2.3 to 2.9 variation is very low but for wall thickness from 2.9 to 3.3 variation rate is still comparatively higher. The variation between actual and theoretical buckling load may be due to variation in chemical composition and the generation of eccentricity, if any. In this paper an attempt has been made to assess the buckling behavior of hollow mild steel column obtained experimentally with respect to the theoretically calculated.

\section{Acknowledgement}

Authors are thankful to Director, CSIR-CIMFR, Dhanbad for this kind permission to do the experimentation with reference to our post graduation research work and publication thereof.

\section{References}

Arbocz J. and Starnes, J H, 2002, Future direction and challenges in shell stability analysis, Thin-Walled Structure, Vol. 40, No. 9, pp-729-754

Akin J.E, 2009, Buckling analysis, Draft 102, downloaded at

https://www.clear.rice.edu/mech403/HelpFiles/FEA_Buckling_analysis.pdf 
Avear M, 2014, Elastic buckling of steel column under axial compression, American Journal of Civil Engineering, Vol.2, No.3, pp. 102-106

Basbiik M, Eryilmaz A and Atay M.T., 2014, On critical buckling loads of columns under end load depends on direction, International Scholarly Research Notices, Vol. 2014, pp. 1-7

Bhoi R, Kalurkar L.G, 2014, Study of buckling behavior of beam and column subject to axial loading for various rolled I section ; International Journal of Innovative Research in Science, Engineering and Technology, Vol.3, No. 11, pp. 1-7

Bystrom J and Kuzmin L, 2013, Circular vs. triangular cross-section: Some thoughts about bending stiffness, downloaded at: www.kuzmin.se/docs/buckling_of_ski_pole_2013.pdf, pp. 1-4

Elishakoff I., 2000, Uncertain buckling: Its past, present and future, International Journal of Solids and Structures, Vol. 37, pp. 6869-6889.

Eryilmaz A, Tarikatay M., Caskun SB and Basbiik M, 2013, Buckling of Euler column with a continuous elastic restraint via homotopy analysis method, Journal of Applied Mathematics, Vol. 2013, pp- 1-9.

Estekanchi H.E, Vafai A., 1999, On the buckling of cylindrical shell with through cracks under axial load, Thin-walled Structures, Vol. 35, No. 4, pp. 255-274

Gendy B.L., Hanna M.T., Effect of geometrical imperfections on the ultimate moment capacity of cold-formed sigma-shape sections, Housing and Building National Research Centre Journal, Vol. 13, No. 2, pp. 163-170

Hutchinson J.W, Tennyson R.C and Uggeridge D.B.M, 1971, Effect of a local axisymmetric imperfection on the buckling behavior of a circular cylindrical shell under axial compression, AIAA Journal, Vol. 9, pp. 1

Johnson W.R, 2018, Study of buckling of conical column, pp-1-5

Khurmi R.S., 2005, Strength of Material, S.Chand Publication, New Delhi, India, pp-723-736.

Li Y-W., James I.E., Starnes H., Bushnell D. 1997, Effect of the thickness variation and initial imperfection on buckling of composite cylindrical shells: Asymptotic analysis and numerical results by BOSOR4 and PANDA2, International Journal of Solids and Structures, Vol. 34, No. 28, pp. 3755-3767

Morris N.F., 1996, Shell stability the long road from theory to practice, Engineering Structures, Vol.18, pp-801-806

Optics, 2018, Buckling and stability, mechanical design in optical design, pp-79-80, downloaded at optics.arizonna.edu/optomech/refrences/OPTI_222/OPTI_222_W16pdf

Palassopoulos G.V., 1993, New approach to buckling of imperfection sensitive structures, Journal of Engineering Mechanics, Vol. 119, No. 4, pp 856-869

Yoontae K., 2011, Buckling of cracked cylindrical shell reinforced with an elastic liner, M.Sc. Degree Thesis, Department of Mechanical and Industrial Engineering, Northeastern University, Boston, Massachusetts, USA, pp:-5 -7

\section{Biographical notes}

Sudhir Kumar Kashyap is a Senior Principal Scientist with CSIR-Central Institute of Mining \& Fuel Research, Dhanbad, India.

Sajal Kumar is a Post Graduate Scholar (Mechanical engineering) B.I.T Sindri Dhanbad, India

Mousumi Mallick is a Senior Scientist, CSIR- Central Institute of Mining \& Fuel Research, Barwa Road, Dhanbad, India

Rudra Pratap Singh is a Senior Principal Scientist, CSIR- Central Institute of Mining \& Fuel Research, Barwa Road, Dhanbad -826015, India

Manoranjan Verma is a Technical Officer, CSIR- Central Institute of Mining \& Fuel Research, Barwa Road, Dhanbad, India

Received January 2018

Accepted March 2018

Final acceptance in revised form July 2018 